\title{
The perception of the elderly about suffering related to frailty
}

Abstract

Objective: To understand how elderly persons perceive subjective aspects linked to current and other life experiences related to the process of becoming frail. Method: A qualitative study, anchored in interpretative anthropology, was performed. The elderly were selected from the FIBRA Network database from those classified as robust or pre-frail, according to the frailty phenotype of Fried et al., in Belo Horizonte, Minas Gerais, Brazil in 2009. We interviewed 15 elderly people of different genders, ages, income, religion and functional status, in 2016. In data collection and analysis, the "signs, meanings and actions" analysis model was used, which allows the understanding of the elements that are significant for a population to read a given situation and to position themselves in relation to it. Results: From the analysis the following categories emerged: a) suffering throughout life and b) suffering and the resources to deal with them. Conclusion: The interviewees described sufferings of different aspects that constitute their life, from birth to aging, according to experiences related to pain, loss and learning. The perception of current frailty refers to their life history, marked by physical or mental suffering, whether insidious or temporary - as well as illnesses, how they manifest themselves today, and a lack of financial resources and urban security. The narratives bring us closer to the perception of frailty as being constitutive of human beings, who can easily break.

\footnotetext{
Fundação Oswaldo Cruz (FIOCRUZ), Programa de Pós-graduação em Saúde Coletiva. Belo Horizonte, Minas Gerais, Brasil.

2 Prefeitura Municipal de Belo Horizonte, Secretaria Municipal da Saúde. Belo Horizonte, Minas Gerais, Brasil.

3 Fundação Oswaldo Cruz (FIOCRUZ), Núcleo de Estudos em Saúde Pública e Envelhecimento (NESPE). Belo Horizonte, Minas Gerais, Brasil.

4 Universidade Federal de Minas Gerais, Escola de Educação Física, Fisioterapia e Terapia Educacional,
} Departamento de Fisioterapia. Belo Horizonte, Minas Gerais, Brasil.

Research funding: Fundação de Amparo à Pesquisa de Minas Gerais (Minas Gerais Research Support Foundation) (FAPEMIG) (APQ-00703-17), Conselho Nacional de Desenvolvimento Científico e Tecnológico (National Council of Scientific and Technological Development) (CNPq). Research grant - 303372/2014-1.

Daniel Rocha Silveira'

Karla Cristina Giacomin ${ }^{2,3}$

Rosângela Correa Dias ${ }^{4}$

Josélia Oliveira Araújo Firmo ${ }^{3}$

Keywords: Frail Elderly. Perception. Fragility. Medical Anthropology. 


\section{INTRODUCTION}

Frailty is a clinical condition in which the individual's vulnerability to dependence or mortality increases in the face of a stressor event ${ }^{1}$. Several groups of researchers have reached the consensus that this multifactorial medical syndrome can be potentially tracked, prevented or treated with specific actions; and that all individuals over 70 years of age or with unintentional weight loss should be assessed.

A major conceptual framework is the frailty phenotype proposed by Fried et al. ${ }^{2}$, which is based on five criteria: unintentional weight loss, self-reported exhaustion, physical weakness, reduced gait speed, and poor levels of physical activity. The presence of three or more criteria configures frailty; one or two, pre-frailty and the absence of all three defines a robust person. According to the literature, the prevalence of the syndrome is higher among women and increases with age - ranging from $2.5 \%$ among the elderly aged between 60 and 70 years, to more than $30 \%$ among octogenarians ${ }^{1}$. In Brazil, based on the same criteria, a cross-sectional, multidisciplinary and multicenter epidemiological study was carried out to investigate the profile and prevalence of this syndrome in the elderly and its associated factors - the Rede de Estudo sobre Fragilidade em Idosos Brasileiros (the Study Network on Frailty Among the Brazilian Elderly) (FIBRA network). The study comprised four centers: the Universidade Federal de Minas Gerais, the Universidade de Campinas, Universidade de São Paulo-Ribeirão Preto and the Universidade do Estado do Rio de Janeiro. Among elderly persons in Belo Horizonte, the prevalence of frailty was $8.7 \%{ }^{3}$.

When investigated in its physical sphere, studies with a notably biomedical and positivist approach describe how the process of becoming frail, although dynamic, usually follows a unidirectional logic: from the robust stage, through pre-frail, culminating in frail. A better understanding of how these transitions occur could support care, prevention and intervention ${ }^{4}$.

In the search for a broader understanding of what constitutes the frailty of an elderly person, other issues should be considered, namely the cultural, psychic and social, which are interrelated and variable from individual to individual ${ }^{5}$. They also include subjective issues about health, disease and the discomforts that people experience throughout life.

The experience of frailty also includes an existential perspective, in which the individual suffers when faced with their own finitude ${ }^{6}$ in the face of the contingencies of life. This highlights the importance of social determinants in the way people age ${ }^{7}$, considering that disorders, whether physical or psychological, are only accessible through cultural mediation ${ }^{8}$.

The present work aims to understand how elderly persons perceive subjective aspects related to current and other suffering experienced during life that relate to the process of becoming frail.

\section{METHOD}

This qualitative approach, anchored in Interpretive Anthropology, assumes culture as a constellation of meanings that becomes the map from which people in a group read each life situation. This understanding made it possible to distinguish between "disease", or the biological process of becoming sick, and "illness", which corresponds to a local cultural construction and to which each person assigns their own meaning ${ }^{10}$. In addition, it is important to consider that the set of values and practices that configure biomedical knowledge can diverge from the set of values and practices that constitutes local popular culture, including the experience of life in the world of the users of the services ${ }^{11}$.

In 2009, the 601 elderly participants of the Belo Horizonte Center of the FIBRA Network were evaluated and classified as robust, pre-frail or frail, according to the frailty phenotype of Fried et al. ${ }^{2}$. After 24 months of follow-up all 40 elderly individuals considered frail at baseline were then reassessed ${ }^{4}$. Eighteen $(45 \%)$ had died or exhibited processes of dementia and reduced physical frailty that made it impossible to conduct interviews. Therefore only those classified as robust or pre-frail were invited to participate in the present study, carried out six years after initial data collection, as the group of elderly considered frail would probably no longer be eligible for interviews. 
The choice of the FIBRA Network was due to the possibility of access to a group of elderly people who had already been investigated on the subject. However, since the scope of the research penetrated the subjective sphere of this process of becoming frail, the methodology used was different from that of FIBRA, which was based on objective physical measurements. The elderly identified as pre-frail and robust were randomly selected from the list of participants in the FIBRA network. To guarantee the heterogeneity of the participants, people of different genders, ages, incomes, religions, functional conditions and places of residence in regions of the city with disparate Human Development Index (HDI) levels were included ${ }^{12}$. Those who presented severe sequelae or some other reason that would not enable them to respond and participate in an interview were not eligible for the study.

All were contacted by telephone and a home interview was scheduled. They were Informed about the study and, after signing the Term of Free and Informed Consent, were interviewed in person. The saturation criterion regulated the sample size ${ }^{13}$.

In the interviews, no concepts of frailty were presented and/or explained to the elderly, since the aim was to understand the participants' perceptions about this phenomenon and to identify in the reports of their experiences if they somehow coincided with the proposed criteria in the frailty phenotype of Fried et al. ${ }^{2}$. All the elderly were encouraged to talk about life and about themselves, more specifically about their health conditions, what their discomforts are, and how they deal with them.

Data collection and analysis were based on the "Signs, meanings and actions" model ${ }^{9}$ that allows the understanding of the significant elements that a population employs to read a given situation and to position itself in relation to it. This methodology starts from the pragmatics, observing the behaviors of the social actors, which allows the forms of interpretation of a concrete situation to be understood. The reports allow the reconstruction of the behaviors, the meanings given to them and the practices assumed from this?. The interpretation seeks to identify the central semiological configurations, in an intertextual context, from the reading of personal narratives in the context of the great cultural narratives?. This model allows a greater systematization of the different elements of the context (such as social dynamics, central cultural codes and the concept of the person) that effectively intervene in the identification of what is problematic, in the decision to treat a problem or not and in the choice of the appropriate therapist'. In this perspective, one leaves the reified object of medicine - the disease - and enters in its place, the subject, considered as a citizen of law who is capable of reflexivity and choosing how to live his or her life ${ }^{10}$.

All the interviews were recorded, transcribed, carefully read and reread and a categorization of the narratives was performed.

This study is part of the "Frailty in the elderly: perceptions, cultural mediation, coping and care", approved by the Ethics Committee of the Instituto René Rachou/Fiocruz (CAE: 49173415.8.0000.5091).

\section{RESULTS AND DISCUSSION}

Fifteen elderly persons (69-86 years) were interviewed, two of whom were also caregivers of their disabled husbands.

Two categories emerged from the analysis: Suffering during the course of life; Illness and lack of resources.

\section{Suffering during the course of life}

In this category, respondents reported suffering from personal and family events that occurred abruptly or insidiously throughout their lives. One interviewee described her experience of the break from reality that resulted in her early retirement and the stigma she carries to this day:

"When I was 30 and I had my third daughter, (...) I took a break, (...) and I suffered so much, and at the time I was doing a master's degree away from work, (...) when I came back, I was forced to retire." (...) "I suffered so much bulling because of my life away from work, in the academic life, you can't imagine what it was like."; "there's a lot of prejudice, a real stigma, everyone calls you crazy. I really suffered from this " (E8, F, 72). 
For Graham et al. ${ }^{14}$, the stigma comes from a process whereby certain individuals and groups of people are made to feel ashamed, excluded and discriminated against. The way a person who has been through a crisis, a psychiatric disorder, is labeled brings a series of sufferings that take various forms, limiting the possibilities of living comfortably with themselves and others ${ }^{15}$. If the crisis and outbreak are the result of a process of social pressures, in a specific individual context, medical and psychotherapeutic treatment can produce effective results. However, they should in no way add to other sufferings arising from the reinforcement of stigmatization and/or iatrogenesis originating from normatizing perspectives suffering which can be as or more painful than the psychiatric condition itself (disease process).

According to Cabral ${ }^{16}$, there are contexts in which different types of suffering are repeated and continue, becoming part of day to day life, so that they are very difficult to digest. An excess of information that affect the entire person and cannot be removed or explained, and which immobilize the creative possibilities. This generates states that imply feelings of powerlessness to deal with a suffocating daily life. In turn, relatives of those who suffer from a "mental illness" demonstrate feelings such as shame and embarrassment, sadness and pity when dealing with the person; and fear that the person will exhibit aggressive behavior ${ }^{17}$. The stigma is present in society, in the family itself, and the person can introject it. A person considered to be "sick" may be frowned upon or pointed out as being in crisis due to behavior that, if it were present - in exactly the same way - in another person who is considered "normal", would not be seen as problematic. Ferreira et al. ${ }^{18}$ emphasize that internalized stigma have negative repercussions on health - the individual self-discriminates, selfrecriminates, feels guilty for having had the crisis, or for "being this way".

Losses of family members and other events identified by respondents as acute suffering that persists to the present - included separation from parents in childhood, the death of a child and widowhood. This man recounts childhood loss arising from his mother's illness - at a time when there were no resources to treat tuberculosis:
“(...) I suffered because my mother and father, who in 1947, when they had seven children... had to give their children away because my mother became tubercular. (...) So I left home, at age five, and did not come back (...) I was becoming a very dependent person." (E12, M, 74).

Many difficulties were described: the move from rural areas to Belo Horizonte, a lack of housing, food restrictions due to a lack of money, disease "spots on the lung" (the speaker had never smoked); toxoplasmosis, having lost $50 \%$ of sight in one eye and $90 \%$ in another, which led to early retirement at age 40 on medical advice. The existential process of this man can be understood as a succession of sufferings, in accordance with what Kleinman describes as "the pain of living" - a life where pain is a constant background and/or foreground, and which occurs in chronic patients.

Among the sufferings that result from the loss of very significant persons, two women emphasized the death of a child and widowhood:

\footnotetext{
"As soon as he left the church, (...) he said: um, my arm hurts. Then he said, let me sit here, (...) when he did so, he fell back, he died. Ah, my boy ... ah, this little piece of me, I won't tell you anymore." (E1, F, 83 years).

"Because I lost my husband ... I lived in the country, so I was very worried because I was going to be without my husband and my children, because the three of them lived here. Then my son said; 'No mom, you're not going to be alone, you're going to live with one of us in Belo Horizonte', so I came, I lived here ... four years with my other son ... and I've been with her longer". (E2, F, 83 years).
}

Changes in roles and family arrangements are related to the process of becoming frail. Widowhood can contribute to the onset of frailty, especially for men, as well as creating new family arrangements ${ }^{20}$. In Brazil, there is an increase in the number of multigenerational households: most often due to the needs of the younger members, who still depend financially on the elderly. However, the notion of reciprocity of care between parents and children, or grandparents and grandchildren, and the expectation that the elderly will be cared for by these family members may not transpire in old age ${ }^{21}$. 
Thus, another condition related to the process of fragilization was the act of caring for dependent elderly people. Because of the need for care, an elderly person may be taken to live with one of their children, usually a daughter. A woman who cares fondly for her mother explains:

"Family is not what we want, it's what we have. (...) you have to live together, but you don't talk about it, you don't try to fix it, because you can't, that's the way it is. "(...) But my mother suffers from it (...)." (E5, F caregiver E2,83).

While this woman expresses her suffering as translated into feelings of resentment and anger about the husband she cares for:

"I neglected myself to look after my husband. (...) I stopped doing my physical activities, going out, dancing, I gave up everything - because of my husband. (...) My marvelous husband, because he had a heart attack, is diabetic, ... aren't you, sir? (...) I take good care of you, right?? (E10, F, 72).

Throughout the interview, she makes it clear that she needs to "care" for someone she does not love and blames the husband for the unhappiness - her and hers - in a repetitive and torturous way. The husband can do nothing except listen to her angry discourse: he is so frail that in a sense he is helpless even in relation to his wife. The relational climate is distressing, the lack of love fills the verbal and nonverbal expressions of the couple. The physical environment, a small apartment, is full, with two children, a daughter-in-law, and several teen grandchildren. The marital conflict is overflowing.

In the specific case of elderly caregivers, inserted in contexts of high vulnerability, conditions for care are even more critical, since the lack of social support and institutional care policies affect social cohesion and the ability of families to respond to adverse situations. These contexts can further weaken the health of caregivers, as well as compromising the quality of life of all involved ${ }^{1}$.

In old age, family conflicts gain visibility and are exposed and revealed. The family, as a complex interactive system, demands constant accommodations, depending on external stressors and changes in internal relationship patterns ${ }^{22}$. In the family, reality is defined by a story that has been told from generation to generation - constituted by language, socially modified, and passed on memberto-member, as verbal and gestural, verbal and nonverbal. Each family group creates its mythology, which is constituted as rules for life, existential guidelines followed by each member without being clearly aware that they are doing so. A person, in this context, can - from their reflections - follow the guidelines and/or build their own paths, with greater or lesser degrees of freedom ${ }^{22}$. In each family, frailty in old age overflows as an outcome of the entire personal construction, embedded in the particular family narrative that is based on a common cultural context.

\section{IInesses and a lack of resources}

In this category, the interviewees identified several types of diseases that appear in the narratives (arthrosis, cancer, heart disease, hypertension, Alzheimer's, poor vision and hearing, falls, pain, among others) and the presence or lack of resources influences this process.

This man says that his physical health is good, but he has a psychological illness:

"Now there are diseases that are psychological, as I have for example, I am a victim, for example, from time to time I have a deep sadness, something is missing." (E12, M, 74).

Other chronic diseases were reported by a man and a woman:

\footnotetext{
"My health is ... so-so ... I have chronic myeloid leukemia, it's under control, do you know what it is? I've already had prostate surgery ... it's ... within the limits ... I'm having treatment ... but it's under control ... all of them ... that's the way it is..." (E4, M, 69).

"I'm 74 years old, and I've been hospitalized three times for heart problems. (...) (...) I was shocked, and so on, but ... we don't check out early." (E11, F, 74).
} 
It is known that the presence of comorbidities and frailty are is interrelated ${ }^{4}$ and should be highlighted in the health care of the elderly. However, in these extracts, the interviewees discuss how a lack of resources compromises this care:

“... everything is very expensive, with just one salary. (...) I have grandchildren, children, I have a daughter who has been unemployed for eight months, my brother [who lives with her and suffers from mental illness] doesn't work. It's just my salary. And I help my granddaughter, who lives in São Paulo, to pay the rent (...). And I help another one who lives nearby (...) the electricity bill and the water bill are late." (E11, F, 74).

“It's difficult. I can't pay anyone to help me (take care of my husband with Alzheimer's). I earn the minimum wage. I do odd jobs to help out. But my salary is our only fixed income. "(E1, F, 83).

In all interviews it was found that in order to deal with the sufferings and limitations that relate to frailty, the category of material resources is fundamental as a basis of support to guarantee care. A woman explains the suffering that occurs because she cannot afford to comfort her husband or herself:

"He's off work, he's sick. (...) I take care of him too ... The boys help me take care of him ... I couldn't bear to buy diapers for him, and I went to the Social Services and I managed to get food - no, not food, supplements, gloves and wet wipes. (...) I want to get what I can, because I can't stand washing the bed linen anymore ... one day he's fine, another he's not, that's the way it is." (E1, F, 83).

In the sample population there is a lack of material, emotional and social resources to cope with chronic care. It is a topic that deserves further study and demands solutions, agreeing with the conclusions of Giacomin and Firmo ${ }^{23}$ : The creation and implementation of a long-term care policy for the elderly in Brazil is essential.

In addition, the idealized conception that the elderly should be able to preserve their health, branding themselves as a "failure" due to their own frailty, becomes a cruel corollary of the view that aging equals illness. At the same time the ideology of "do it yourself" relieves the family, the state and society from the responsibility of providing favorable conditions for care and protection in old age $^{23}$. The blame for the disease, from a normative perspective, characterizes in part the biomedical approach - which seeks to provide a form of care and treatment, but can become a type of violence and coercion, which is also evident from the research of Moraes et al. ${ }^{24}$.

Two elderly persons emphasized the fact that they modified their daily activities due to the lack of safety in the city:

\begin{abstract}
"Moving around the city without a car, having to take the bus, rude people in the street, is a health risk, to my own health, so I decided to stop. (...) You can't go out in the street (...) So, I try to lead a quieter life (...) (E12, M, 74).

" Life outside the home is different from life at home - so we end up spending more time at home than going out, which is no good" (E10, F, 72).
\end{abstract}

The interviewees perceived the city as a source of risk. The lack of financial resources and urban safety were pointed out as a source of discomfort that hinders a good quality of life and compromises the health of individuals, which corroborates the study of Danielewicz et al. ${ }^{25}$.

Respondents did not at any time use the terms "frailty", "frail" or "becoming frail". They speak of a world of their own, the experiential world, which constitutes an anthropological reality - historical, social, psychic, of the elderly human being. If the frailty phenotype proposed by Fried et al. ${ }^{2}$ was used as a reference, the elderly emphasized only two of the five proposed criteria: the aspects of mobility and loss of energy - which is translated as "lack of enthusiasm", as in these excerpts:

"I have noticed, a decline, a ... over the years, that I'm lose my ability to do things every day. And with every year that passes my physical activities are more limited (...) It was easier to move. Because, when you get to my age, I think my balance is not what it was. I do not know if it's because of wear and tear." (E10, F, 72).

"I was really down in the dumps. But now I'm feeling better (...). I was feeling very low". (E2, F, 83) 
The marking of the passage of time corresponds to a "natural" process of becoming frail that is confused with old age, which is almost always associated with illness and debilitation, ideas that are part of the Western historical imaginary ${ }^{23,24}$. Although it is accepted that there are "elderly diseases ", when they describe their difficulty in understanding why certain diseases do not have medical treatment, a lack of pharmacological and biomedical resources is used to as an explanation to solve the experience of sickness and sadness of old people. The pain that medicine does not heal can also be understood as the "pain of living"19 and the characteristic of frailty of human beings and our "essence of glass"',

Moraes et al. ${ }^{24}$ confirm that the elderly perceive biomedical knowledge to be lacking, seeing it as a knowledge that doctors prescribe but which does not value the experience of the person. It does not provide true care, therefore, because it does not account for the suffering that goes beyond the diagnoses and treatment protocols, as well as naturalizing illness as being synonymous with old age. Kleinman ${ }^{19}$ explains this distance between biomedicine and the daily life of the "patient". The medical academy and the local life of the elderly are distinct worlds, just as the perception about health and disease differs in different cultures.

Suffering is part of living, in the history of every person, in every stage of life. However, it is only when one listens and understands, from the approach of standing alongside the individual ${ }^{19}$, that strategies can be sought to deal with such discomforts and try, if possible, to overcome them.

\section{REFERENCES}

1. Morley JE, Vellas B, Van Kan GA, Anker SD, Bauer JM, Bernabei R, et al. Frailty consensus: a call for action. J Am Med Dir Assoc. 2013;14(6):392-7.

2. Fried LP, Ferrucci L, Darer J, Williamson JD, Anderson G. Untangling the concepts of disability, frailty, and comorbidity: implications for improved targeting and care. J Gerontol Ser A Biol Sci Med Sci. 2004;59(3):255-63.

\section{CONCLUSION}

Although it is not possible to achieve a univocal concept of frailty, the interviewees narrate the sufferings undergone in different aspects that constitute their life, from birth to aging, according to experiences that represent pain, loss, learning. The perception of current frailty refers to one's life history, marked by physical or mental suffering, insidious or temporary - as well as the illnesses, the way they are today, and the lack of financial resources and urban security.

The narratives bring us closer to the perception of frailty as being constitutive of human beings which can easily break. In aging, the perception of oneself as frail increases - although frailty is always present from birth. By feeling that one is the bearer of a "nature" that can shatter, the awareness of the importance of caring grows, and the possibility of realizing more comprehensive syntheses of life itself.

Careful listening to the experiences of the elderly enables health care and health promotion strategies to become more respectful and effective, ensuring greater adherence to proposals that promote good quality of life. In this sense, the importance of constructing educational resources, training health professionals, supporting families, and of insertion into cultural manifestations - at a broad social level - is evident, with the optimization of resources that contribute to a more real, humanized and broader development of the elderly and their richness and creative potential - so that the quality of life of older persons improves.

3. Vieira RA, Guerra RO, Giacomin KC, Vasconcelos KSS, Andrade ACS, Pereira LSM, et al. Prevalência de fragilidade e fatores associados em idosos comunitários de Belo Horizonte, Minas Gerais, Brasil: dados do Estudo FIBRA. Cad Saúde Pública. 2013;29(8):1631-43.

4. Faria GS, Ribeiro TMS, Vieira RA, Silva SLA, Dias RC. Transition between frailty levels in elderly persons from Belo Horizonte, Minas Gerais, Brazil. Rev Bras Geriatr Gerontol. 2016;19(2):335-41. 
5. Fernandes MGM, Andrade NA, Nóbrega MML. Antecedentes de fragilidade no idoso: uma revisão sistemática. Online Braz J Nurs [Internet] 2010 [acesso em 18 dez. 2017];9(1):1-8. Disponível em: http://www.objnursing.uff.br/index.php/nursing/rt/ printerFriendly/2847/649

6. Carrière JC. Fragilidade. Rio de Janeiro: Editora Objetiva; 2007.

7. Vidal EIO. Fragilidade em idosos: perspectivas para a pesquisa e a prática em Saúde Coletiva. Cad Saúde Pública. 2014;30(6):1133-5.

8. Geertz C. A interpretação das culturas. Rio de Janeiro: LTC; 2008.

9. Corin E, Uchôa E, Bibeau G, Koumare B. Articulation et variatons des systèmes de signes, de sens et d'actions. Psychopathol Afr. 1992;24(2):183-204.

10. Kleinman A. Patients and healers in the context of culture. Berkeley: University of California Press; 1980.

11. Uchôa E, Firmo JOA, Lima-Costa MF, Corin E. An anthropologic study on strategies for addressing health problems among the elderly in Bambuí, Minas Gerais State, Brazil. Cad Saúde Pública. 2011;27 Suppl 3:370-7.

12. Instituto Brasileiro de Geografia e Estatística. Belo Horizonte: IBGE; 1991-. Cidades; 2010 [acesso em 15 jul 2017]; [aproximadamente 2 telas]. Disponível em: www.ibge.gov.br

13. Minayo MCS. Amostragem e saturação em pesquisa qualitativa: consensos e controvérsias. Rev Pesqui Qual. 2017;5(7):1-12.

14. Graham N, Lindesay J, Katona C, Bertolote JM, Camus V, Copeland JRM, et al. Redução da estigmatização e da discriminação das pessoas idosas com transtornos mentais: uma declaração técnica de consenso. Rev Psiquatr Clín. 2007;34(1):39-49.

15. Clemente AS, Santos WJ, Nicolato, R, Firmo JOA. Stigma related to bipolar disorder in the perception of psychiatrists from Belo Horizonte, Minas Gerais State, Brazil. Cad Saúde Pública. 2017;33(6):1-10.
16. Cabral S. Marcas de resiliência ou sobre como tirar leite de pedra. In: Cabral S, Cyrulnik B, organizadores. Resiliência: como tirar leite de pedra. São Paulo: Casa do Psicólogo; 2015. p. 57-74.

17. Vicente JB, Mariano PP, Buriola AA, Paiano M, Waidman MAP, Marcon SS. Aceitação da pessoa com transtorno mental na perspectiva dos familiares. Rev Gaúcha Enferm. 2013;34(2):54-61.

18. Ferreira GCL, Silveira PS, Noto AR, Ronzani TM. Implicações da relação entre estigma internalizado e suporte social para a saúde: uma revisão sistemática da literatura. Estud Psicol. (Natal) [Internet]. 2014 [acesso em 17 dez. 2017];19(1):77-86. Disponível em: http://www.scielo.br/scielo.php?script=sci_ arttext\&pid=S1413-294X2014000100010

19. Kleinman A. The art of medicine Caregiving: the odyssey of becoming more human. Lancet. 2009;373(9660):292-3.

20. Maciel GMC, Da Silva HTA, Gonçalves RG, Ferreira JDL, Tietre SV, Menezes RMP. Frailty assessment and its association with sociodemographic and health characteristics in community elderly. Int Arch Med. 2017;10(134):1-7.

21. Lima-Costa MF, Peixoto SV, Malta DC, Szwarcwald CL, Mambrini JVM. Cuidado informal e remunerado aos idosos no Brasil (Pesquisa Nacional de Saúde, 2013). Rev Saúde Pública. 2017;51 Supl 1:1-9.

22. Sarti CA. A família como ordem simbólica. Psicol USP. 2004;15(3):11-28.

23. Giacomin KC, Firmo JOA. Velhice, incapacidade e cuidado na saúde pública. Ciênc Saúde Coletiva. 2015;20(12):3631-40.

24. Moraes GVO, Giacomin KC, Santos WJ, Firmo JOA. A percepção dos idosos sobre o saber biomédico no cuidado à velhice e às "coisas da idade". Physis. 2016;26(1):309-29.

25. Danielewicz AL, Wagner KJP, D’Orsi E, Boing AF. Is cognitive decline in the elderly associated with contextual income? Results of a population-based study in southern Brazil. Cad Saúde Pública. 2016;32(5):1-11. 